\title{
Off-pump hepatic to azygos connection via thoracotomy for relief of fistulas after a Kawashima procedure: Ten-year results
}

\author{
Sara C. Arrigoni, $\mathrm{MD},{ }^{\mathrm{a}}$ Freek van den Heuvel, $\mathrm{MD}, \mathrm{PhD},{ }^{\mathrm{b}}$ Tineke P. Willems, $\mathrm{MD}, \mathrm{PhD},{ }^{\mathrm{c}}$ Hans Hillege, $\mathrm{MD}, \mathrm{PhD},{ }^{\mathrm{d}}$ \\ Harald L. Lindberg, MD, PhD, ${ }^{\mathrm{e}}$ Rolf M. F. Berger, MD, PhD, ${ }^{\mathrm{b}}$ and Tjark Ebels, $\mathrm{MD}, \mathrm{PhD}^{\mathrm{a}}$
}

\section{ABSTRACT}

Objectives: An almost universal incidence of developing pulmonary arteriovenous fistulas after the Kawashima operation has been reported. Exclusion of the hepatic venous flow from the pulmonary circulation causes the development of these malformations. Redirection of hepatic venous flow to the pulmonary circulation mostly leads to the regression of the arteriovenous fistulas.

Methods: We analyzed 11 patients with arteriovenous fistulas that developed after the Kawashima operation. The hepatic-to-azygos shunts were performed with an off-pump technique through a lateral thoracotomy in all but one. Operative and postoperative data were retrospectively collected.

Results: No intraoperative complications occurred, and no patient died in the hospital. Up to 10-year follow-up showed a significant postoperative improvement of patients' oxygen saturation and New York Heart Association class. Apart from 2 re-thoracotomies for bleeding in 1 patient, no complications occurred and no patient died during follow-up. Two other patients underwent reoperation for an undiagnosed additional hepatic vein. The improvement of patients' oxygen saturation and New York Heart Association class persisted during the follow-up period.

Conclusions: The surgical connection can be performed safely with an off-pump technique that avoids the risks related to extracorporeal circulation and circulatory arrest. The results at 10 years follow-up confirmed the efficacy and safety of the surgical technique described. (J Thorac Cardiovasc Surg 2015;149:1524-30)

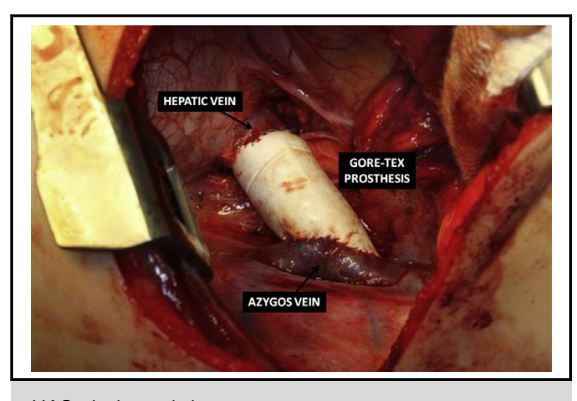

HAS via lateral thoracotomy.

\section{Central Message}

The HAS by interposition of a vascular prosthesis can be performed safely with an offpump technique through a lateral thoracotomy. The redirection of hepatic venous flow to the pulmonary circulation leads to the regression of arteriovenous fistulas.

\section{Perspective}

The redirection of the hepatic blood to the pulmonary bed can be performed with different techniques and approaches. We describe the HAS by using a polytetrafluoroethylene (GoreTex; WL Gore \& Associates Inc, Flagstaff, Ariz) vascular prosthesis performed with an off-pump technique through a lateral thoracotomy. The described technique is safe and has excellent clinical results at short- and mediumterm follow-ups. This technique avoids the risks of repeat sternotomy and the possible complications related to the cardiopulmonary bypass. Moreover, the extracardiac connection provides adequate and balanced flow distribution of the hepatic blood to both lungs.

See Editorial Commentary page 1530.

\footnotetext{
From the Departments of Congenital Cardiothoracic Surgery, ${ }^{\mathrm{a}}$ Pediatric Cardiology, Radiology, ${ }^{\mathrm{c}}$ and Epidemiology, ${ }^{\mathrm{d}}$ University Medical Centre Groningen, Groningen, The Netherlands; and Department of Thoracic and Cardiovascular Surgery, Oslo University Hospital, Oslo, Norway.

Received for publication Nov 25, 2014; revisions received Feb 17, 2015; accepted for publication Feb 21, 2015; available ahead of print March 24, 2015.

Address for reprints: Sara C. Arrigoni, MD, Thoraxcentrum, University Medical Center Groningen, University of Groningen, PO Box 30.001, Hanzeplein 1, 9700 RB, Groningen, The Netherlands (E-mail: s.c.arrigoni@umcg.nl).

$0022-5223 / \$ 36.00$

Copyright (C) 2015 by The American Association for Thoracic Surgery

http://dx.doi.org/10.1016/j.jtcvs.2015.02.049
}

In 1984, Kawashima and colleagues ${ }^{1}$ described a quasitotal cavopulmonary connection in patients with univentricular atrioventricular connection, interrupted inferior caval vein, and azygos or hemiazygos continuation where the superior caval vein was connected to the right pulmonary artery, leaving the hepatic veins connected to the atrium. Kawashima and colleagues ${ }^{1}$ published their surgical technique 4 years before de Leval and colleagues ${ }^{2}$ first publication on the total cavopulmonary connection. The "Kawashima operation" is currently a recognized surgical technique to achieve a quasi-complete cavopulmonary 


\section{Abbreviations and Acronyms \\ CT = computed tomography \\ HAS = hepatic to azygos shunt \\ ICU = intensive care unit \\ NYHA $=$ New York Heart Association}

connection in cases of interruption of the inferior caval vein, which usually occurs in the context of left atrial isomerism. $^{3,4}$

However, the medium- and long-term follow-ups after the Kawashima operation show a high incidence of gradually reducing systemic oxygen saturation due to the formation of pulmonary arteriovenous fistulas. ${ }^{5-7}$ It was suggested that the exclusion of hepatic venous blood flow from the pulmonary circulation caused the development of arteriovenous fistulas. ${ }^{5-8}$ The reversibility of these arteriovenous fistulas after redirection of hepatic venous blood flow to the pulmonary circulation supported the concept that a lack of a hitherto unidentified hepatic factor in the pulmonary blood causes the development of the fistulas. ${ }^{7-10}$ Different techniques have been described to redirect the hepatic flow to the pulmonary circulation, and we described the current technique in 2008., 11-14 In our study, we describe an off-pump technique to make a connection between the hepatic vein and the azygos or hemiazygos vein using a vascular prosthesis through a lateral thoracotomy. We report on the outcomes up to 10 years of 11 patients in whom this technique was used to redirect hepatic flow to the lungs.

\section{MATERIAL AND METHODS}

\section{Study Design: Patient Selection}

The Institutional Review Boards of the University Medical Center Groningen and Rikshospitalet Oslo University Hospital agreed to waive the need for an informed consent because data were collected as part of routine medical care and patients were not individually identifiable.

We selected from both institutional databases those patients who underwent a surgical connection of the hepatic to the azygos vein, hepatic to azygos shunt (HAS), because of the development of arteriovenous fistulas after a Kawashima operation. The operations were performed between June 2002 and August 2011; thus, the maximum follow-up is 10 years.

Inclusion criteria were a prior Kawashima operation with secondary hypoxia due to pulmonary arteriovenous fistulas. Twelve patients satisfied the inclusion criteria. One patient was excluded because of refusal until now of the surgical procedure. The presence of arteriovenous fistulas was suspected by a progressive decrease of oxygen saturation by pulse oximetry during follow-up compared with the oxygen saturation recorded immediately after the Kawashima operation. Three patients had similar oxygen saturation levels before HAS compared with the time of their Kawashima operation. However, these patients showed poor clinical condition and cyanosis at exercise. The presence of pulmonary arteriovenous fistulas demonstrated by contrast echocardiography and cardiac catheterization determined the indication to proceed with the HAS procedure.
Two-dimensional contrast echocardiography was used in all patients to confirm the presence of pulmonary arteriovenous fistulas. This was performed by injection of agitated saline solution through a peripheral vein with simultaneous echocardiographic imaging of the left atrium. Pulmonary arteriovenous fistulas were considered present when contrast could be visualized in the left atrium with a short delay (3-5 cardiac cycles or 2-4 seconds) after contrast injection. In 9 patients, in addition to contrast echocardiography, cardiac catheterization was performed to visualize the fistulas and reduced oxygenation of pulmonary venous blood established.

A computed tomography (CT) angiography examination was performed to define the anatomy with particular focus on the connection between the hepatic veins and the atrium. Contrast was injected in an antecubital vein, and after 40 seconds the scan was started so optimal hepatic vein enhancement was obtained. The $\mathrm{CT}$ data were reconstructed on a 3-dimensional workstation by using a multiplanar reformat and volume-rendering technique.

\section{Data Collection and Patients' Characteristics}

Preoperative, operative, and postoperative data from all 11 patients were collected retrospectively. Baseline patient characteristics are listed in Table 1.

\section{Surgical Technique}

Ten HAS procedures were performed through a thoracotomy, and 1 HAS procedure was performed through a median re-sternotomy. The surgical approach was planned on the basis of the CT scan findings, where the thoracotomy was done on the same side as the major inferior systemic vein, thus, right in case of an azygos continuation and left in case of a hemiazygos continuation. The HAS procedures were performed through a left thoracotomy in 7 patients with a hemiazygos continuation and through a right thoracotomy in 3 patients with an azygos continuation. All operations were performed off pump, as previously described. ${ }^{9}$ Through a thoracotomy at the level of the seventh or eighth intercostal space, the hepatic vein and the azygos or hemiazygos vein could be identified easily. A polytetrafluoroethylene (Gore-Tex; WL Gore \& Associates Inc, Flagstaff, Ariz) vascular prosthesis was used to make the connection. The diameter of the vascular prosthesis varied between 10 and $18 \mathrm{~mm}$. The choice of the polytetrafluoroethylene (Gore-Tex) vascular prosthesis diameter depends on the diameter of the hepatic vein and the azygos or hemiazygos vein: The prosthesis diameter should be proportional to both veins.

The hepatic vein was partially closed by using a side-biting vascular clamp. An end-to-side anastomosis was performed between the polytetrafluoroethylene (Gore-Tex) vascular prosthesis and the hepatic vein. Afterward, an end-to-side anastomosis was performed between the polytetrafluoroethylene (Gore-Tex) vascular prosthesis and the azygos or hemiazygos vein by partial closure of the azygos or hemiazygos vein, again with a side-biting vascular clamp. After de-airing, the shunt was opened and started functioning (Figure 1).

The connection of the hepatic veins to the atrium was always closed by using a suture or staples. A division of the hepatic vein could be performed where there was enough space to place 2 vascular clamps or to use a combined stapler/cutting device. The division was performed in 2 patients.

All patients received postoperative acetylsalicylic acid at a dosage of 100 $\mathrm{mg}$ daily per os in adult patients and at a weight-based dosage in pediatric patients. In the presence of atrial arrhythmia, previous thromboembolic events, and thrombophilia, such as factor V Leiden or protein C/S deficiency, patients received vitamin $\mathrm{K}$ antagonist instead of acetylsalicylic acid. The international normalized ratio target was between 2 and 3. It was recommended to continue lifelong antithrombotic or anticoagulation therapy. At follow-up, all patients were still receiving antithrombotic or anticoagulation treatment.

\section{Follow-up}

The clinical follow-up was performed at regular outpatient visits. Physical examination, echocardiographic evaluation, laboratory tests, measurement of oxygen saturation by pulse oximetry, and evaluation of New York Heart Association (NYHA) class were routinely performed in all patients. 
TABLE 1. Patients' preoperative characteristics

\begin{tabular}{|c|c|c|c|c|c|c|}
\hline $\begin{array}{l}\text { Patient } \\
\text { (gender) }\end{array}$ & Cardiac anomalies & $\begin{array}{l}\text { IVC connection/ } \\
\text { cardiac position }\end{array}$ & $\begin{array}{c}\text { Side of } \\
\text { thoracotomy }\end{array}$ & $\begin{array}{l}\text { Bilateral } \\
\text { SVCs }\end{array}$ & $\begin{array}{l}\text { Other } \\
\text { noncardiac } \\
\text { congenital } \\
\text { anomalies }\end{array}$ & $\begin{array}{l}\text { Previous } \\
\text { palliative } \\
\text { operation }\end{array}$ \\
\hline $1(\mathrm{~F})$ & $\begin{array}{l}\text { Left atrial isomerism, double outlet right ventricle, } \\
\text { AVSD, subvalvar pulmonary stenosis }\end{array}$ & $\begin{array}{l}\text { Hemiazygos to } \\
\text { LSVC/levocardia }\end{array}$ & Left & Yes & $\begin{array}{l}\text { Situs inversus } \\
\text { abdominalis }\end{array}$ & None \\
\hline $2(\mathrm{~F})$ & $\begin{array}{l}\text { Left atrial isomerism, pulmonary valve atresia, outlet } \\
\text { VSD, ASD }\end{array}$ & $\begin{array}{l}\text { Hemiazygos to } \\
\text { LSVC/levocardia }\end{array}$ & Left & Yes & & $\begin{array}{l}\text { 1. BT shunt left } \\
\text { 2. BT shunt right }\end{array}$ \\
\hline $3(\mathrm{~F})$ & $\begin{array}{l}\text { Left atrial isomerism, double inlet left ventricle, AVSD, } \\
\text { transposition great vessels, pulmonary valvar stenosis }\end{array}$ & $\begin{array}{l}\text { Azygos to } \\
\text { RSVC/levocardia }\end{array}$ & Right & No & & None \\
\hline $4(\mathrm{~F})$ & $\begin{array}{l}\text { Left atrial isomerism, double outlet right ventricle, } \\
\text { atrioventricular discordance, pulmonary valvar and } \\
\text { pulmonary arterial stenosis }\end{array}$ & $\begin{array}{l}\text { Azygos to } \\
\text { RSVC/levocardia }\end{array}$ & $\begin{array}{l}\text { Median } \\
\text { sternotomy }\end{array}$ & No & & $\begin{array}{l}\text { 1. Atrioseptostomy } \\
\text { 2. BT shunt left } \\
\text { 3. BT shunt right }\end{array}$ \\
\hline $5(\mathrm{M})$ & $\begin{array}{l}\text { Left atrial isomerism, double outlet right ventricle, } \\
\text { AVSD, subvalvar and pulmonary valvar stenosis, VSD }\end{array}$ & $\begin{array}{l}\text { Hemiazygos to } \\
\text { LSVC/levocardia }\end{array}$ & Left & No & $\begin{array}{l}\text { Situs inversus } \\
\text { abdominalis }\end{array}$ & BT shunt right \\
\hline $6(\mathrm{M})$ & $\begin{array}{l}\text { Left atrial isomerism, AVSD, Hypoplastic right } \\
\text { ventricle, right SVC to coronary sinus }\end{array}$ & $\begin{array}{l}\text { Hemiazygos to } \\
\text { LSVC/dextrocardia }\end{array}$ & Left & No & & $\begin{array}{l}\text { Pulmonary artery } \\
\text { banding }\end{array}$ \\
\hline $7(\mathrm{M})$ & $\begin{array}{l}\text { Left atrial isomerism, double outlet right ventricle, } \\
\text { AVSD, right sided azygos vein }\end{array}$ & $\begin{array}{l}\text { Azygos to } \\
\text { RSVC/levocardia }\end{array}$ & Right & No & & $\begin{array}{l}\text { Pulmonary artery } \\
\text { banding }\end{array}$ \\
\hline $8(\mathrm{M})$ & $\begin{array}{l}\text { Left atrial isomerism, AVSD, situs inversus, arch } \\
\text { hypoplasia, aortic atresia }\end{array}$ & $\begin{array}{l}\text { Hemiazygos to } \\
\text { LSVC/levocardia }\end{array}$ & Left & Yes & $\begin{array}{l}\text { Situs inversus } \\
\text { abdominalis }\end{array}$ & $\begin{array}{l}\text { Norwood stage I } \\
\text { with Sano shunt }\end{array}$ \\
\hline $9(\mathrm{~F})$ & $\begin{array}{l}\text { Left atrial isomerism, double discordance, situs inversus, } \\
\text { pulmonary atresia, VSD }\end{array}$ & $\begin{array}{l}\text { Azygos to } \\
\text { RSVC/levocardia }\end{array}$ & Right & No & & Central shunt \\
\hline $10(\mathrm{~F})$ & $\begin{array}{l}\text { Right atrial isomerism, situs ambiguus, hypoplastic right } \\
\text { ventricle }\end{array}$ & $\begin{array}{l}\text { Hemiazygos to } \\
\text { LSVC/levocardia }\end{array}$ & Left & Yes & $\begin{array}{l}\text { Situs inversus } \\
\text { abdominalis }\end{array}$ & None \\
\hline $11(\mathrm{~F})$ & Left atrial isomerism, mitral atresia & $\begin{array}{l}\text { Hemiazygos to } \\
\text { LSVC/levocardia }\end{array}$ & Left & No & & $\begin{array}{l}\text { Pulmonary artery } \\
\text { banding }\end{array}$ \\
\hline
\end{tabular}

$\overline{A S D}$, Atrial septal defect; $A V S D$, atrial ventricle septal defect; $B T$, Blalock-Taussig; $I V C$, inferior vena cava; $L S V C$, left superior vena cava; $R S V C$, right superior vena cava; $S V C$, superior vena cava; $V S D$, ventricle septal defect.

\section{Data Management and Statistical Analysis}

Statistical analysis was performed using IBP SPSS Statistics 22 (IBM Corp, New York, NY). Values are reported as mean, range, median, or percentages. A paired-samples test ( $t$ test) was used to compare preoperative and postoperative oxygen saturation. A sign test was used to compare preoperative and postoperative NYHA class.

\section{RESULTS}

Figure 2 shows the variability of time interval between the Kawashima operation and the HAS operation in terms

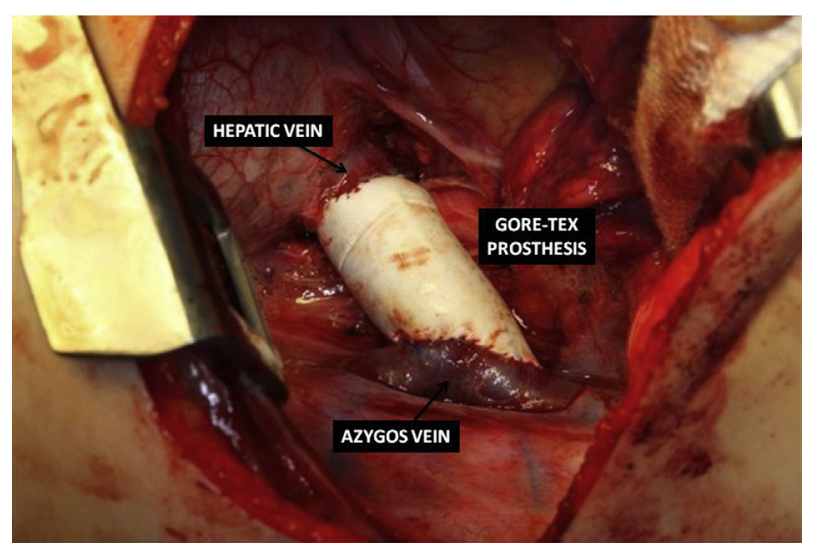

FIGURE 1. Intraoperative exposition of the hepatic veins and azygos vein through a lateral thoracotomy. of patients' age. The mean patients' age at Kawashima operation was 4.5 years. The median age was 2 years and ranged from 5 months to 25 years.

The mean patients' age at the HAS operation was 10.8 years. The median age was 11 years and ranged from 2 to 30 years. The median interval between Kawashima and HAS operation was 6 years and ranged from 2 to 14 years (Figure 2). Figure 3 shows the cumulative freedom from HAS reoperation after the Kawashima operation.

\section{In-Hospital Course}

No intraoperative complications occurred. In 1 patient, 2 re-thoracotomies were performed because of postoperative bleeding. No patient died in the hospital.

The median length of hospital stay was 12 days, with a range from 7 to 54 days. One patient had a prolonged ward stay ( 52 days) because of pleural effusion that required prolonged chest tube drainage. The median length of intensive care unit (ICU) stay was 1 day, with a range from 1 to 11 days. One patient remained in the ICU for 11 days because of logistic problems and was discharged on postoperative day 12. The median length of hospital and ICU stay is similar to those reported in other studies. $3,14,15$ 


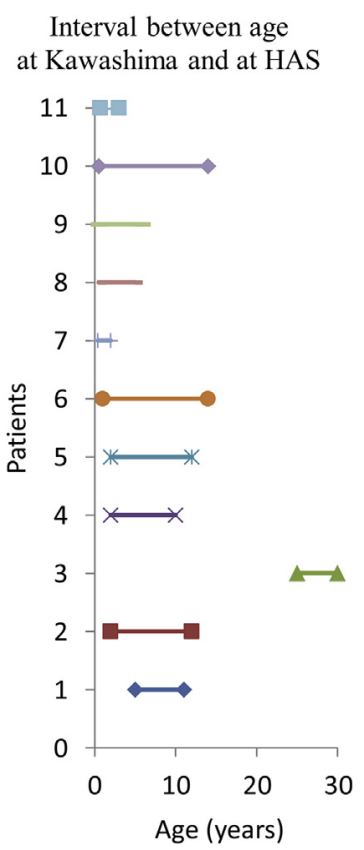

FIGURE 2. Time interval between Kawashima operation and HAS related to patients' age. HAS, Hepatic to azygos shunt.

All patients were extubated within the first postoperative day. One patient required inotropic support by means of dopamine during the first 12 postoperative hours. Prolonged pleural effusion ( $>3$ days) was detected in 4 patients and was treated with prolonged chest drainage.

\section{Follow-up}

The first postoperative outpatient clinic controls were performed within the first year after surgery. One patient was readmitted to the hospital 4 months after the operation because of poor clinical condition and persistent low oxygen saturation. An angiography showed a residual ipsilateral connection between the hepatic veins and the atrium, which required a reoperation. The reoperation was performed through a left re-thoracotomy. The residual connection between 1 hepatic vein and the atrium was closed, resulting in an increase in oxygen saturation (up to $92 \%$ ).

Figure 4 shows the course of the oxygen saturation of each patient. The graph shows the decreased oxygen saturations before the HAS if compared with the values after the Kawashima operation. After the HAS, the oxygen saturations increased again at least up to the value measured immediately after the Kawashima operation. There was a significant difference $(P=.0001)$ between the mean oxygen saturation before and 3.5 months after the HAS operation: $78 \%$ versus $94 \%$.

Figure 5 shows patients' NYHA class evaluation before and after the HAS operation. There is a significant difference $(P<.001)$ between the preoperative NYHA class (median class III) and the postoperative NYHA class (median class I). The mean follow-up time was 42 months and ranged from 6 months to 10 years.

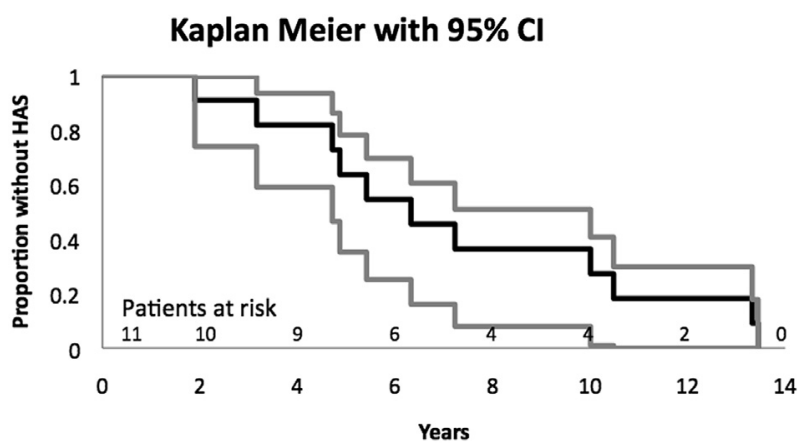

FIGURE 3. Kaplan-Meier curve. Cumulative freedom from HAS reoperation after Kawashima operation. $C I$, Confidence interval; $H A S$, hepatic to azygos shunt.

One patient was readmitted to the hospital 3 years after the operation because of progressive edema, ascites, and cyanosis. The oxygen saturation at readmission was $79 \%$, whereas the saturation at 1 -year follow-up was $100 \%$. A CT scan showed the presence of a contralateral connection between the left hepatic veins and the common atrium. This connection was not recognized at the time of the previous operation when the HAS was performed on the right hepatic veins only. A reoperation was performed through a left thoracotomy with an off-pump technique. The connection between the left hepatic veins and the common atrium was closed with an immediate increase in oxygen saturation (up to $98 \%$ ). At the following outpatient controls, the saturation remained stable at $95 \%$ to $100 \%$.

No patient died during the follow-up. No other complications occurred during the follow-up. One patient had persistent peripheral edema. Eight patients had NYHA class I, and 3 patients had NYHA class II.

\section{DISCUSSION}

The almost universal incidence of pulmonary arteriovenous fistulas after the Kawashima operation has been described in several studies. ${ }^{5-7}$ Redirection of the hepatic flow to the pulmonary bed leads to progressive resolution of the arteriovenous fistulas, supporting their reversible nature. ${ }^{7-12}$ The progressive resolution of the arteriovenous fistulas generally occurs within the first year after the operation. ${ }^{11,12}$

We have described a successful off-pump technique through a lateral thoracotomy, allowing for adequate distribution of the elusive hepatic factor to both lungs. The operation generally is performed through a median sternotomy; the drawbacks are that much of the heart then needs to be dissected, cardiopulmonary bypass is needed, and even deep hypothermic circulatory arrest is often reported. ${ }^{11,12,15}$ Both techniques involve risks. Pediatric cardiac surgery with cardiopulmonary bypass can be associated with neurodevelopmental impairment. ${ }^{16,17}$ The increasing duration of deep hypothermic circulatory arrest is directly associated 


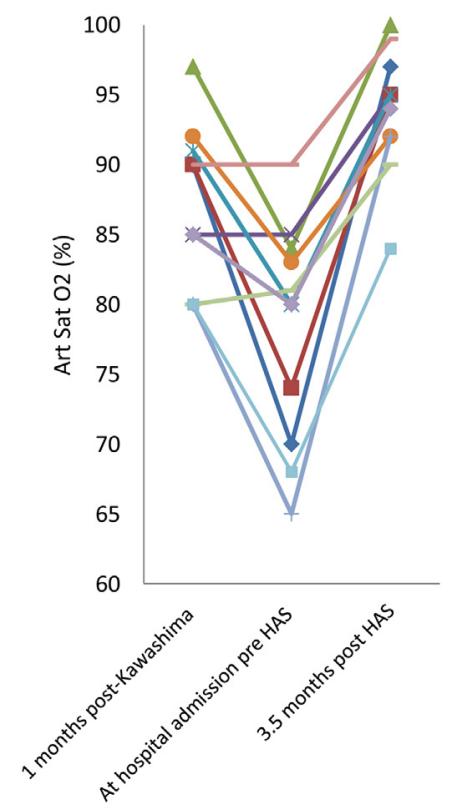

FIGURE 4. Arterial oxygen saturation recorded immediately after Kawashima operation and before and after HAS per patient. Art Sat O2, Arterial oxygen saturation; HAS, hepatic to azygos shunt.

with adverse long-term neurodevelopmental sequelae. ${ }^{18} \mathrm{~A}$ further complicating factor in patients with cyanotic heart disease, including our cohort of patients, is the effect of the aortopulmonary collateral circulation on flow distribution during cardiopulmonary bypass. This collateral pulmonary circulation can divert a variable portion of the systemic circulating blood, sometimes making it difficult to maintain an adequate flow and perfusion pressure. ${ }^{19}$ Also, the collateral pulmonary circulation can negatively influence the cerebral oxygenation during hypothermic cardiopulmonary bypass. ${ }^{19}$ The risks of a repeat median sternotomy in the congenital population are mainly related to possible reentry injuries. ${ }^{20,21}$ Although the use of pericardial substitutes can reduce retrosternal adhesions, the risk of injuries is not negligible.

Furthermore, the duration of the dissection maneuvers can influence the resource use and the related costeffectiveness of the procedure. ${ }^{20}$ In our study, we perform the surgical connection of the hepatic to the azygos vein with an off-pump technique through a lateral thoracotomy. In our series, there was no need for conversion to cardiopulmonary bypass or median sternotomy. A lateral thoracotomy allows an optimal exposition of both the hepatic veins and the azygos vein (Figure 1). No intraoperative complications occurred, and all patients survived the operation. Therefore, we argue that this off-pump connection of the hepatic to the azygos vein through a lateral thoracotomy is a safe technique that eliminates the risks related to the use of cardiopulmonary bypass or circulatory arrest. Moreover, the approach through a lateral thoracotomy avoids the risks of reentry injuries related to a repeat sternotomy and allows a satisfied surgical exposure.

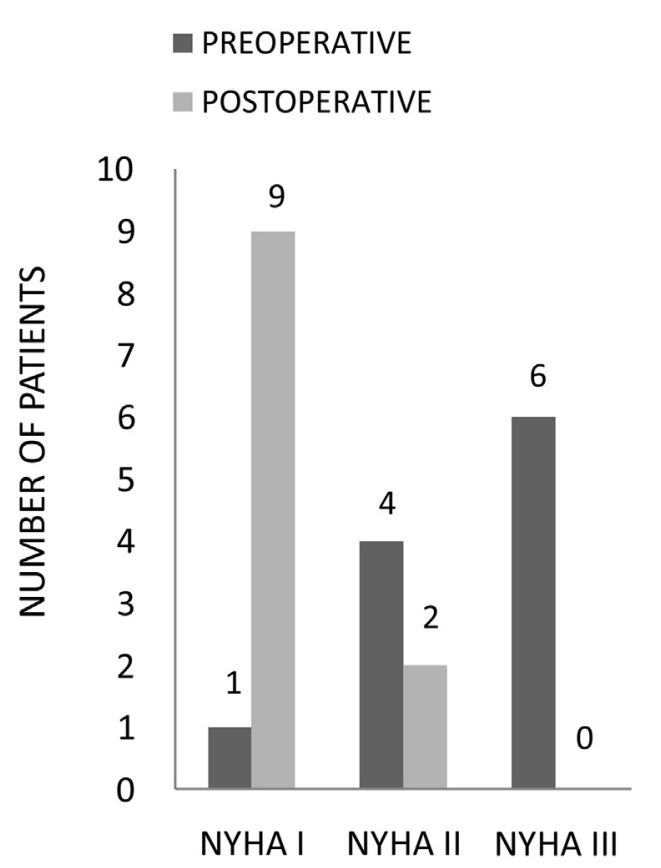

FIGURE 5. Patients' NYHA class before and after HAS. NYHA, New York Heart Association.

A further advantage of the extracardiac HAS is the apparently adequate flow distribution of the hepatic blood to both lungs. The intracardiac hepatic venous baffle may lead to an unbalanced hepatic flow distribution to the left and right lungs, and in turn to unilateral pulmonary arteriovenous fistulas. ${ }^{22,23}$

The results of 1-year follow-up showed a significant postoperative improvement of patients' oxygen saturation (94\% vs $78 \%$ ) and a significant postoperative improvement of patients' NYHA class (III vs I). This clinical improvement in our patients after the redirection of the hepatic flow to the pulmonary circulation supports the notion of reversibility of arteriovenous fistulas.

At the end of follow-up, the mean oxygen saturation in our patient group was $95 \%$, and all patients had a functional NYHA class I or II. No patient died during the follow-up. These follow-up results further support the safety and long-lasting efficacy of the HAS at medium term.

Although the incidence of arteriovenous fistulas after the Kawashima operation is almost universal, the time interval between the Kawashima operation and the development of these fistulas is highly variable, as confirmed in our study (Figure 5). Therefore, the timing to perform the redirection of the hepatic flow to the pulmonary bed remains arguable.

Some authors suggested redirecting the hepatic flow very soon after the Kawashima operation to prevent the development of the arteriovenous fistulas, rather than cure them at a later stage. ${ }^{6,15}$ Amodeo and colleagues ${ }^{24}$ described a Kawashima operation combined with the direct hepatic to azygos 
connection. Sathe and colleagues ${ }^{25}$ performed a banding of the pulmonary trunk to allow a limited antegrade flow to prevent the development of fistulas. We have to consider that in the setting of patients after the Kawashima operation, the HAS corresponds to the Fontan completion and therefore to the gradual attrition of the circulatory reserve. This physiologic course can result in many systemic complications, such as hepatic dysfunction, protein-losing enteropathy, plastic bronchitis, and arrhythmias. ${ }^{26,27}$

Moreover, the prosthetic material used for the connection between the hepatic vein and the azygos vein can increase the risk for thromboembolic events by promoting thrombus formation. ${ }^{28}$ Therefore, our policy is not to perform the HAS shortly after the cavopulmonary connection in the absence of arteriovenous fistulas. Our institutional policy consists of periodical outpatient follow-up evaluations after the Kawashima operation. The timing of the HAS is established on the basis of initial signs of development of arteriovenous fistulas: oxygen saturation lower than $85 \%$, presence of symptoms, and decreased exercise capacity. Regular outpatient controls allow the timely recognition of the development of malformations. Furthermore, the reversibility of the malformations after the HAS does not necessitate a preventive operation at short term.

To reduce the risk for thromboembolic events by thrombus formation promoted by the prosthetic material used for the HAS connection, our institutional policy consists of antithrombotic treatment and if indicated anticoagulation treatment in all patients after the HAS operation. Thromboembolic events occurred in none of the patients at follow-up.

For the preoperative diagnosis, it is essential to know in detail all the anatomic connections because the pattern of hepatic vein drainage may vary, and this information is needed for the success of the procedure. The timing of the scan after the injection of the contrast is essential to optimize the hepatic vein enhancement. The hepatic drainage in hearts with isomeric left appendages can be isolated or through independent channels: It can be bilateral on both sides of the vertebrae $^{13}$ or follow another pattern, such as a partial drainage through the coronary sinus. ${ }^{29}$ In our study, it was necessary to perform a reoperation twice in the same patient because of the presence of bilateral hepatic vein drainage that was not recognized by the first HAS operation. If this had been recognized before the first operation, it would have had implications on the surgical technique. In case of a contralateral connection of the hepatic vein, it is necessary to create an intra-atrial tunnel to connect the bilateral hepatic veins. We used this technique in 1 of the patients with a recognized contralateral connection. However, this patient was aged 5 years at the time of HAS, whereas the other patient was aged 25 years at the time of the operation. We can argue that in adult patients, it could be more difficult to reach the hepatic vein to create the tunnel through a contralateral thoracotomy. Therefore, in adult patients, it could be easier to perform a median sternotomy or to connect the bilateral hepatic veins by using a vascular prosthesis.

\section{Study Limitations}

The main limitation of our study is the limited number of patients. The small number of patients may have influenced the statistical significance of the Cox regression analysis.

\section{CONCLUSIONS}

Our results show that the off-pump hepatic to azygos connection through a lateral thoracotomy is a safe surgical technique for the completion of a total cavopulmonary connection in the setting of a previous Kawashima procedure. This technique avoids the risks related to the extracorporeal circulation and circulatory arrest and demonstrates excellent clinical results at short- and medium-term follow-ups.

\section{Conflict of Interest Statement}

Authors have nothing to disclose with regard to commercial support.

\section{References}

1. Kawashima Y, Kitamura S, Matsuda H, Shimazaki Y, Nakano S, Hirose H. Total cavopulmonary shunt operation in complex cardiac anomalies. A new operation. J Thorac Cardiovasc Surg. 1984;87:74-81.

2. de Leval MR, Kilner P, Gewillig M, Bull C. Total cavopulmonary connection: a logical alternative to atriopulmonary connection for complex Fontan operations. Experimental studies and early clinical experience. J Thorac Cardiovasc Surg. 1988;96:682-95

3. Kawashima Y, Matsuki O, Yagihara T, Matsuda H. Total cavopulmonary shunt operation. Semin Thorac Cardiovasc Surg. 1994;6:17-20.

4. Kutty S, Frommelt MA, Danford DA, Tweddell JS. Medium-term outcomes of Kawashima and completion Fontan palliation in single-ventricle heart disease with heterotaxy and interrupted inferior vena cava. Ann Thorac Surg. 2010;90: 1609-13.

5. Vollebregt A, Pushparajah K, Rizvi M, Hoschtitzky A, Anderson D, Austin C, et al. Outcomes following the Kawashima procedure for single-ventricle palliation in left atrial isomerism. Eur J Cardiothorac Surg. 2012;41:574-9.

6. Brown JW, Ruzmetov M, Vijay P, Rodfeld MD, Turrentine MW. Pulmonary arteriovenous malformations in children after the Kawashima operation. Ann Thorac Surg. 2005;80:1592-6.

7. Jacobs ML, Mavroudis C. Challenges of univentricular physiology in heterotaxy. World J Pediatr Congenit Heart Surg. 2011;2:258-63.

8. Srivastava D, Preminger T, Lock JE, Mandell V, Keane JF, Mayer JE Jr, et al. He patic venous blood and the development of pulmonary arteriovenous malformations in congenital heart disease. Circulation. 1995;92:1217-22.

9. Lopez FE, van den Heuvel F, Waterbolk TW, Ebels T. Off-pump connection of the hepatic to the azygos vein through a lateral thoracotomy for relief of arterio-venous fistulas after a Kawashima procedure. Cardiol Young. 2008;18: 311-5.

10. Kawashima Y. Cavopulmonary shunt and pulmonary arteriovenous malformations. Ann Thorac Surg. 1997;63:930-2.

11. Shah MJ, Rychik J, Fogel MA, Murphy JD, Jacobs ML. Pulmonary AV malformations after superior cavopulmonary connection: resolution after inclusion of hepatic veins in the pulmonary circulation. Ann Thorac Surg. 1997;63:960-3.

12. McElhinney DB, Kreutzer J, Lang P, Mayer JE Jr, del Nido PJ, Lock JE. Incorporation of the hepatic veins into the cavopulmonary circulation in patients with heterotaxy and pulmonary arteriovenous malformations after a Kawashima procedure. Ann Thorac Surg. 2005;80:1597-603.

13. Uemura H, Yagihara T, Hattori R, Kawahira Y, Tsukano S, Watanabe K. Redirection of hepatic venous drainage after total cavopulmonary shunt in left isomerism. Ann Thorac Surg. 1999;68:1731-5. 
14. Waterbolk TW, Talsma MD, Loef BG, Slooff MJ, Ebels T. Increasing cyanosis after total cavopulmonary connection treated by banding a separate liver vein. Ann Thorac Surg. 1995;59:1226-8.

15. Burstein DS, Mavroudis C, Puchalski MD, Stewart RD, Blanco CJ, Jacobs ML. Pulmonary arteriovenous malformations in heterotaxy syndrome: the case for early, direct hepatic vein-to-azygos vein connection. World J Pediatr Congenit Heart Surg. 2011;2:119-28.

16. Gessler P, Schmitt B, Prètre R, Latal B. Inflammatory response and neurodevelopmental outcome after open-heart surgery in children. Pediatr Cardiol. 2009; 30:301-5.

17. Tárnok A, Schneider P. Pediatric cardiac surgery with cardiopulmonary bypass: pathways contributing to transient systemic immune suppression. Shock. 2001; 16(Suppl 1):24-32.

18. Gaynor JW, Nicolson SC, Jarvik GP, Wernovsky G, Montenegro LM, Burnham NB, et al. Increasing duration of deep hypothermic circulatory arrest is associated with an increased incidence of postoperative electroencephalographic seizures. J Thorac Cardiovasc Surg. 2005;130:1278-86.

19. Sakamoto T, Kurosawa H, Shin'oka T, Aoki M, Isomatsu Y. The influence of pH strategy on cerebral and collateral circulation during hypothermic cardiopulmonary bypass in cyanotic patients with heart disease: results of a randomized trial and real-time monitoring. J Thorac Cardiovasc Surg. 2004;127:12-9.

20. Morales D, Williams E, John R. Is resternotomy in cardiac surgery still a problem? Interact Cardiovasc Thorac Surg. 2010;11:277-86.

21. Kirshbom PM, Myung RJ, Simsic JM, Kramer ZB, Leong T, Kogon BE, et al. One thousand repeat sternotomies for congenital cardiac surgery: risk factors for reentry injury. Ann Thorac Surg. 2009;88:158-61.

22. de Zélicourt DA, Haggerty CM, Sundareswaran KS, Whited BS, Rossignac JR, Kanter KR, et al. Individualized computer-based surgical planning to address pulmonary arteriovenous malformations in patients with a single ventricle with an interrupted inferior vena cava and azygous continuation. Thorac Cardiovasc Surg. 2011;141:1170-7.

23. Sundareswaran KS, de Zélicourt D, Sharma S, Kanter KR, Spray TL, Rossignac J, et al. Correction of pulmonary arteriovenous malformation using image-based surgical planning. JACC Cardiovasc Imaging. 2009;2: 1024-30.

24. Amodeo A, Di Carlo D, Grigioni M, De Santis M, Di Donato RM. Early primary Kawashima operation combined with direct hepatic vein-to-azygos vein connection: a new logical approach. J Thorac Cardiovasc Surg. 2005;129: 949-50.

25. Sathe Y, Chidambaram S, Manohar K, Cherian KM. Staged Kawashima operation with cavopulmonary connection. J Thorac Cardiovasc Surg. 2012;144: 267-8.

26. Mondésert B, Marcotte F, Mongeon FP, Dore A, Mercier LA, Ibrahim R, et al. Fontan circulation: success or failure? Can J Cardiol. 2013;29:811-20.

27. Anderson PA, Sleeper LA, Mahony L, Colan SD, Atz AM, Breitbart RE, et al. Contemporary outcomes after the Fontan procedure: a Pediatric Heart Network multicenter study. J Am Coll Cardiol. 2008;52:85-98.

28. Jahangiri M, Kreutzer J, Zurakowski D, Bacha E, Jonas RA. Evaluation of hemostatic and coagulation factor abnormalities in patients undergoing the Fontan operation. J Thorac Cardiovasc Surg. 2000;120:778-82.

29. Uemura H, Ho SY, Devine WA, Kilpatrick LL, Anderson RH. Atrial appendages and venoatrial connections in hearts from patients with visceral heterotaxy. Ann Thorac Surg. 1995;60:561-9.

Key Words: Fontan procedure, congenital heart defect, collateral circulation, thoracotomy

\section{EDITORIAL COMMENTARY}

\section{When is palliation permanent?}

Peter B. Manning, MD

See related article on pages 1524-30.

I recall from early in my training a mentor routinely referring to staged reconstruction for single ventricle cardiac defects as "permanent palliation," implying that although complete cavopulmonary connection may afford a physiologic correction with separation of the systemic

From the Division of Cardiothoracic Surgery, St Louis Children's Hospital, St Louis, Mo.

Disclosures: Author has nothing to disclose with regard to commercial support.

Received for publication March 5, 2015; accepted for publication March 6, 2015; available ahead of print April 11, 2015.

Address for reprints: Peter B. Manning, MD, Division of Cardiothoracic Surgery, St Louis Children’s Hospital, St Louis, MO 63110 (E-mail: manningp@ wudosis. wustl.edu).

J Thorac Cardiovasc Surg 2015;149:1530-1

0022-5223/\$36.00

Copyright $(\odot) 2015$ by The American Association for Thoracic Surgery

http://dx.doi.org/10.1016/j.jtcvs.2015.03.009 and pulmonary circulations, there remained long-term liability inherent with the lack of a pulmonary ventricle. In 1984, Kawashima and associates described an experience of 4 patients with "presently uncorrectable cyanotic cardiac anomalies." Patients with heterotaxia and anomalies of systemic venous drainage were at the time thought to be impossible to manage in the manner that was being proposed

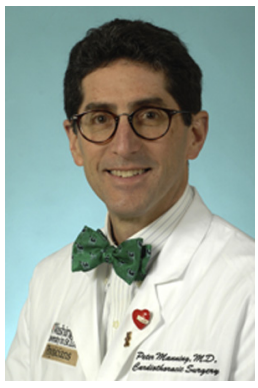
for other single ventricle anomalies. They described a "total cavopulmonary shunt operation" for patients with azygos or hemiazygos continuation of the absent inferior vena cava that became eponymously named the "Kawashima" operation. Although they recognized this operation did not constitute a complete diversion of systemic venous return to the pulmonary arteries, leaving the "hepatocardiac venous and coronary sinus flow" to continue to bypass the lungs, they anticipated that this would result in a 